\title{
El hábito conceptual y la distinción entre los universales lógicos y reales según Tomás de Aquino
}

\author{
JUAN FERNANDO SELLÉS \\ Departamento de Filosofía \\ Universidad de Navarra \\ jfselles@unav.es
}

\begin{abstract}
Resumen: En este trabajo se sostiene que el acto del concepto depende del hábito conceptual. El primero conoce dos causas de la realidad física: la material y la formal. Una de ellas, la formal, es el universal real (unum) que se da en pluralidad de sujetos materiales (in multis). El universal real es diferente del universal lógico. El hábito conceptual no conoce las causas, sino los actos de concebir. Por tanto, permite distinguir entre el acto de la razón que conoce el universal real y el acto que conoce el universal lógico.
\end{abstract}

Palabras clave: acto del concepto, hábito conceptual, universales lógicos, universales reales

\begin{abstract}
This paper defends that the act of the concept depends on the conceptual habit. The act of the concept knows two real causes of physical reality: material and formal. One of them, the formal cause, is the real universal (unum) which is present in a plurality of material subjects (in multis). The real universal is different from the logical universal. The habit does not know of causes, but the acts of the concept. So, it permits to distinguish between the act of knowledge that knows the real universal and the act that knows the logical universal.
\end{abstract}

Key words: act of the concept, conceptual habit, logical universals, real universals

En el corpus tomista son abundantes las referencias al acto de concebir y a lo concebido por él, incluso con el mismo vocablo, ${ }^{1}$ pero no al hábito conceptual. Tampoco encontramos referencias a este hábito en los comentadores tomistas y en la bibliografía actual. Con todo, sabemos que existe un hábito conceptual porque la voluntad puede usar del acto de concebir, ya que "puede retener en el interior el concepto del enten-

\footnotetext{
${ }^{1}$ En efecto, en algunos pasajes Tomás de Aquino usa el término de "conceptio" para referirse tanto al acto como a lo conocido: "conceptio autem intellectus est vel operatio ipsa quae est intelligere, vel species intellecta. Unde oportet quod verbum vel dicatur ipsa operatio intelligendi, vel ipsa species quae est similitudo rei intellectae" (In I Sent., d. 27, q. 2, a. 2, qc. a, co.).
} 
dimiento, u ordenarlo hacia lo externo", ${ }^{2}$ y es claro que, para Tomás de Aquino, la voluntad no puede actuar sobre los actos de la inteligencia a menos que esta facultad disponga de los hábitos respectivos. ${ }^{3}$

A continuación, en las cuatro primeras secciones que siguen, se procederá a presentar los diversos hábitos racionales que versan sobre los actos de la razón que permiten conocer la índole de la realidad física. Esos tres actos son muy atendidos en la bibliografía tomista. Como es sabido, éstos son concebir, juzgar y demostrar. Sin embargo, sus respectivos hábitos — salvo el del juicio (al que también se le denomina de ciencia) - son bastante desconocidos o casi por completo. Estos hábitos son el conceptual, el ya aludido hábito judicativo o de ciencia y el hábito de los principios lógicos. En este trabajo nos centraremos en el hábito conceptual. Ahora bien, antes de abordarlo, debemos distinguirlo del hábito abstractivo. Hay distinción entre ambos, como la hay entre sus respectivos actos, abstraer y concebir, y como lo hay entre sus respectivos asuntos conocidos: las especies y el verbo. ${ }^{4}$

Por lo demás, si no se distingue entre abstracto y concepto, no se nota que se pueden formar ideas sobre el abstracto, es decir, ideas generales que no son intencionales respecto de la realidad física, sino exclusivamente sobre los abstractos. Tales ideas equivalen a lo que la tradición escolástica denomina universales lógicos. Éstos no se deben confundir con los universales reales, que - como veremos- equivalen a las causas formales físicas, que se conocen exclusivamente en el concepto. A esta distinción —advertida ya por Lonergan -5 aluden las expresiones del corpus tomista "intentio intellecta" y "res intellecta"; también "species

${ }^{2}$ S. Theol., I, q. 107, a. 1, ad 1. Otra alusión a este hábito parece ser: "nos non totum id quod habitu scimus, actu mente concipimus, sed de uno intelligibili movemur ad aliud; inde est quod in nobis non est unum solum verbum mentale, sed multa, quorum nullum adaequat nostram scientiam" (Quodl., IV, q. 4, a. 1 co.).

${ }^{3}$ Cfr. In II Sent., d. 39, q. 1, a. 2, ad 5; De Malo, q. 16, a. 8, co.; De Vir., q. 1, a. 7, co.; id., q. 1, a. 11, ad 14; In Ethic., 1. IV, lec. 6, n. 12; id., 1. VI, lec. 9, n. 8; In De An., 1. II, lec. 2, n. 6; Super ad Col., lec. 3, cap. 3; S. C. Gentes, 1. IV, cap. 70, n. 2; S. Theol., I-II, q. 52, a. 3 co.; id., q. 53, a. 3 co.; id., q. 63, a. 2, ad 2; S. Theol., III, q. 27 , a. 5 , ad 3 .

${ }^{4}$ Esta distinción es aceptada, entre otros, por Y. Floucat, Lintime fécondité de l'inteligence. Le verbe mental selon saint Tomas d'Aquin; y por C. Trotmman, "Verbe mental et noetique thomiste dans le De verbo d'Herve de Nédellec", pp. 47-62.

${ }^{5}$ Cfr. B. Lonergan, La Notion de verbe dans les écrits de saint Thomas d'Aquin, p. 11. Este autor añade que la expresión "quod quid est" se refiere a la definición, es decir, a la "intentio intellecta", mientras que "quod quid erat esse" se refiere a la causa formal real. Cfr. id., pp. 24-25. No estoy de acuerdo, en cambio, en que "le concept est la définition", (id., p. 43), porque la definición es la expresión lógica del concepto.

Diánoia, vol. LIII, no. 61 (noviembre 2008). 
intellecta" y "species rei"; 6 y asimismo "abstracción formativa" y "abstracción aprehensiva", 7 o, sin más, "species"8 y "verbo". 9 La primera se refiere al objeto mental; la segunda, en cambio, a la causa formal física. ${ }^{10}$ Por lo demás, consideramos irrelevante para nuestro propósito la discusión reciente acerca de si el tema tomista del verbo mental tiene como fuente la filosofía (Aristóteles) o la teología (Agustín de Hipona), pues en ambos contextos está presente. ${ }^{11}$

\section{Los hábitos racionales}

Tras la abstracción —que es el acto preliminar de la inteligencia-, y su hábito correspondiente —el hábito abstractivo—, ${ }^{12}$ Tomás de Aquino explica que se abren dos posibles caminos para la inteligencia, a los cuales denomina abstracción formal y abstracción total. ${ }^{13}$ La vía de abs-

6 "La première species est une forme; la seconde est un universele" (id., p. 126).

7 “Tandis que l'abstraction appréhensive n'est pas de conditions matérielles elle n'est cependant pas à l'écart de ces conditions. C'est l'abstracción formative qui constitue l'objet qui se tient à l'écart des conditions matérielles... en termes d'universel, l'abstraction appréensive connît l'universel dans un cas particulier; l'abstraction formative connaît l'unversel qui est commun à plusieurs" (id., p. 188). Con todo, llamar a ambos actos "abstracción" es equívoco, porque sólo abstrae el primero, no el concepto.

${ }^{8}$ Cfr. Quodl., V, q. 5, a. 2 co.

9 "Necesse est quod species intelligibilis, quae est principium operationis intellectualis, differat a verbo cordis, quod est per operationem intellectus formatum; quamvis ipsum verbum possit dici forma vel species intelligibilis, sicut per intellectum constituta" (Quodl., IV, q. 4, a. 1, co.).

${ }^{10}$ La precedente distinción no se suele advertir por un motivo psicológico usual: la prisa. En efecto, los diversos autores pasan demasiado rápido del concepto al juicio y a la demostración, y de éstos al hábito de los primeros principios, a la sabiduría y al intelecto agente. Pero en teoría del conocimiento conviene demorarse en cada acto y en su tema propio; en distinguir cada acto de sus respectivas expresiones lógicas y lingüísticas. Ese apresuramiento conlleva que se pasen por alto algunos actos de la inteligencia humana, que no se perfilen bien los temas conocidos por éstos y, sobre todo, que se describan de modo poco preciso los hábitos y sus temas. En estos puntos se intentará incidir a continuación.

${ }^{11}$ Cfr. sobre este tema: J. O'Callaghan, "Verbum mentis: Philosophical or Theological Doctrine in Aquinas?", pp. 103-119; J.C. Doig, “O'Callaghan on verbum mentis in Aquinas", pp. 233-255; J. O'Callaghan, "More Words on the verbum: A Response to James Doig", pp. 257-268.

12 "Cum autem intellectus possibilis iam fuerit per species intelligibiles perfectus, vocatur intellectus in habitu, cum species intelligibiles iam sic habet ut eis possit uti cum voluerit" (Comp. Theol., I, 83).

${ }^{13}$ Cfr., para estos actos, mi trabajo: Conocer y amar, pp. 269-288. 
tracción formal considera únicamente la forma —en el sentido de figu$r a-$ que presenta el abstracto. A ese acto siguen otros que consideran parcialmente esa figura, la unen a otras o la aplican a la imaginación; y también siguen hábitos que se corresponden con esos actos. De este estilo son - los ejemplos proceden de Tomás- la lógica, las matemáticas, la retórica, la sofística, etcétera. ${ }^{14}$

En cambio, la vía de abstracción total (o vía racional) atiende cada vez más al contenido del abstracto para conocer progresivamente la índole de la realidad física. En esta vía se abren paso una serie de actos distintos de los de la vía de abstracción formal. Esta línea también se puede llamar vía positiva, en el sentido que procede recuperando lo real, no generalizando lo mental. La primera operación de esta línea es la que los clásicos llaman concepto: se trata del acto de concebir. El primer acto de la vía racional, señala Tomás de Aquino, toma el nombre de la concepción, del dar a luz materno, porque parece que la razón dé a luz, conciba. Ya no se trata de ver las ideas tal cual están en la mente, asunto relativamente cómodo para la mente, sino de conocer cómo es la índole de la realidad física de la que las ideas se han abstraído. Para ello, la mente tiene que, por así decir, abajarse, para percatarse de la naturaleza de lo físico sin elevarlo a su propio nivel.

Lo que precede implica distinguir entre abstracto y concepto o verbo, ${ }^{15}$ y considerar que el concebir es superior al abstraer. Suele decirse que el objeto propio del entendimiento humano es la quidditas rei materialis. ${ }^{16}$ Con todo, si esta quididad se supone separada de las realidades

${ }^{14}$ Cfr. In Post Anal., I, 1, n. 6; id., I, 13, n. 7; In Metaphys., IV, 4, n. 7; id., XI, 3, n. 11; S. Theol., I, 83, 1, co.; id., I-II, 53, 1, co.

${ }^{15}$ Esta distinción pasa inadvertida a la mayor parte de comentadores y estudiosos del tomismo. Al margen de los términos, y prescindiendo de cuál es primera o segunda, Lonergan distingue entre "l'abstraction qui suppose la formation d'un verbe intérieur et qui procure la connaissance de rem ut separatam a conditionibus materialibus sine quibus in rerum natura non existit" y "l'abstraction appréhensive anterieure, decrite dèjá comme intuition pénétrant le phantasme; son objet est different, quant au mode, de l'objet de l'abstaction formative du concept, car par elle l'homme connaît non pas l'objet abstrait de pensée, l'universel commun à plusieurs, mais l'universel existant dans le singulier, la quidditas sive natura in materia corporali existens" (op. cit., p. 157).

${ }^{16}$ Cfr. In I Sent., d. 14, q. 5, ad 7; id., d. 38, q. 1, a. 3 co.; In IV Sent., d. 49, q. 2 , a. 1 co.; De Ver., q. 1, a. 12 co.; id., q. 22, a. 1 ad 8; Quodl., VIII, q. 2, a. 2 co.; In de Anima, 1. III, 8, n. 18 y 19; Comp. Theol., I, 85; In Boet. De Trin., 3, 5, 2 ad 2; C. Gentes, 1. III, cap. 41, n. 3 y 4; id., cap. 108, n. 4; S. Theol., I, q. 17, a. 3, ad 1; id., q. 84 , a. 7 co.; id., q. 85 , a. 5 co. y ad 3 ; id., q. 85 , a. 8 co.; id., q. 86 , a. 2 , co.; id., q. 88 , a. 3 co.

Diánoia, vol. LIII, no. 61 (noviembre 2008). 
materiales, debe tomarse al abstracto como el objeto propio del entendimiento humano, porque éste es, obviamente, separado. Pero si, en cambio, la quididad equivale a la sustancia,${ }^{17}$ naturaleza, ${ }^{18}$ forma, ${ }^{19} \mathrm{e}$ incluso a la esencia, ${ }^{20}$ el objeto propio del entendimiento humano será la causa formal, y ésta se alcanza en el concepto. En efecto, si el intelecto conoce la quididad formal y la real, ello indica que el abstracto es primero y el concepto segundo; que el primero conoce la forma mental y el segundo la forma real. Consecuentemente, será superior conocer la forma de lo real que la sola forma en la mente. Pero como la forma real no está separada de la materia, conocer la causa formal será inseparable de conocer la causa material; es decir, ambas causas se conocerán en concausalidad.

Cuando se quiere conocer más la realidad física, no se puede quedar en el abstracto, sino que se tiene que concebir lo que hay en la realidad, pero según la realidad es, no como se presenta en el abstracto de la mente. Mientras que el abstracto es presente — es lo presentado por el acto de abstraer, al que se le puede llamar presencia-, en la realidad física ninguna realidad existe en puro presente, pues el presente es sin movimiento $y$, en consecuencia, sin tiempo, mientras que en lo físico no hay nada que sea sin movimiento. No hay nada inmutable, por tanto; todo es acto potencial. En ese ámbito, nunca nada ha terminado de suceder. Para conocerlo en su índole causal, la mente tiene que enfrentarse con el estatus de lo real. Para inmiscuirse en su contenido, tiene que ejercer más su capacidad cognoscitiva que la empleada al abstraer, y eso es concebir. El esfuerzo mental no es físico, y no es otra cosa que aportar más conocimiento. Se da más conocimiento por parte

${ }^{17}$ Cfr. In I Sent., d. 8, q. 4, a. 2 ad 1; In Metaphys., 1. V, lect. 10, n. 5; id., VII, lect. 5, n. 19; Quodl., II, q. 2, a. 2 co.

${ }^{18}$ Cfr., In I Sent., d. 8, q. 5, a. 1 co. y 2 co.; id., d. 33, q. 1, a. 1 ad 1; id., d. 35, q. 1, a. 4 co.; In II Sent., d. 3, q. 1, a. 1 co.; In III Sent., d. 5. q. 3, a. 1 co.; Quodl., II, q. 2, a. 2 co.; id., 4, 2, n. 6; In Metaphys., 1. VII, lect. 2, n. 1; id., 1. VII, lect. 3, n. 7; $S$. Theol., I, q. 5, a.3, ad 1.

${ }^{19}$ Cfr. In I Sent., d. 25, q. 1, a. 4 co. y ad 1; id., d. 26, q. 1, a. 1 ad 3; In Metaphys., 1. VII, lect. 7, n. 10; id., 1. VII, lect. 9, n. 10; In Boet. De Trin., 3, 5, 2 ad 2.

${ }^{20}$ Cfr., In I Sent., d. 19, q. 5, a. 1 co.; id., d. 23, q. 1, a. 1 co.; id., d. 25, q. 1, a. 4 ad 2; In II Sent., d. 3, q. 1, a. 1 co. y ad 1; In III Sent., d. 5, q. 1, a. 2 co.; In IV Sent., d. 12, q. 1, a. 1 ad 2; id., d. 49, q. 2, a. 3, ad 5; id., d. 49, q. 2, a. 7 ad 6; De Ver., q. 1, a. 1 co.; Quodl., II, q. 2, a. 2 co.; De Pot., q. 9, a. 1 co.; In Metaphys., 1. V, lect. 10, n. 5; id., VII, lect. 2, nn. 1 y 30; id., 1. VII, lect. 3, n. 7; S. C. Gentes, I, cap. 12 , n. 8 ; id., cap. 21 , n. 2 ; id., 1. III, cap. 3. 49, n. 6; S. Theol., I. q. 88, a. 2 ad 4 , etc. 
de la mente cuando centramos nuestra atención en concebir que en abstraer.

Conceptualizar es recuperar la causa formal y la causa material de la realidad física, implícitas en el abstracto. Se trata del conocimiento del universal real. Tomás - siguiendo al Estagirita- distingue dos universales: uno lógico, y otro real. ${ }^{21}$ La forma, entendida como causa formal, es el universal real, el unum in multis, el uno presente en los muchos particulares materiales (causa material). El fundamento in re del universal del que hablan los medievales del siglo XIII (S. Alberto Magno, Sto. Tomás de Aquino, etc.) lo descubrió Aristóteles; se trata de la causa formal; por ejemplo, la forma de "perro" siendo ésta individualizada en la causa material de los diversos perros existentes. De conocer el concepto universal real imbricado en multiplicidad de individuos, carece de sentido plantearse el problema de cómo puede nuestra inteligencia conocer lo singular, si su objeto abstracto es universal mientras que el de la imaginación es particular. ${ }^{22}$ Carece, asimismo, de sentido plantear la existencia de diversos grados de abstracción, ${ }^{23}$ pues si el concebir es superior al abstraer, y recupera lo real físico, la clave de la prosecución cognoscitiva no será la progresiva abstracción, sino la sucesiva recuperación de la índole de lo físico.

\section{El concepto y el hábito conceptual}

La noción de sustancia (forma en materia) es conocida al concebir. Las dos causas, la material y la formal, que no se pueden dar separadamente en la realidad sustancial, se descubren al concebir. Además, en ese conocimiento uno se da cuenta que la que lleva la delantera es la

21 "Universale potest uno modo considerari quasi separatum a singularibus sive per se subsistens, ut Plato posuit, sive secundum sententiam Aristotelis secundum esse quod habet in intellectu [...]. Alio modo attribuitur universali prout est a singularibus" (In Peri Her., I, 10); "Universale possit considerari in abstractione a singularibus vel secundum quod est in ipsis singularibus" (id). A este respecto defiende Polo que "el concepto no es cuestión de articulación ni de generalidad, sino de universalidad: no es lo mismo la idea general que el concepto universal... La palabra idea se vincula a la generalidad y el concepto a la universalidad. No hay ideas universales sino generales" (L. Polo, Curso de teoría del conocimiento, vol. III, p. 56). Y en otro lugar añade: "El concepto no es una idea general con determinaciones particulares, sino la confrontación de la unidad verbal que es el concebir, la operación, que se sabe con el hábito, como unum in multis, que es la solución física de la cuestión" (El conocimiento racional de la realidad, p. 118).

${ }^{22}$ Cfr. B. Lonergan, op. cit., p. 179.

${ }^{23}$ Cfr. J. Maritain, Distinguir para unir o los grados del saber, 1968.

Diánoia, vol. LIII, no. 61 (noviembre 2008). 
causa formal, porque es la que formaliza, actúa como acto, respecto de la causa material, siendo ésta pasiva respecto de aquélla. Si se comparan diversas sustancias, se hace algo más que concebir ésta u otra sustancia. Esa comparación es imposible sin el hábito de concebir, que ilumina diversos actos de concebir referentes a diversas sustancias. De esa comparación resulta la noción de ente: "lo que es". Así se nota que todas las sustancias son ente. En consecuencia, la noción de ente no es la suprema de la metafísica por doble motivo: uno, porque es la más baja; otro, porque no es una noción metafísica, sino de la filosofía de la naturaleza y responde a un conocimiento común de los compuestos hilemórficos. Por eso, no es adecuado hablar de "entes de razón", porque si se adopta ese uso lingüístico, se tiende a dotar a los "objetos intencionales" de cierta realidad, aunque sea pequeña. De ese estilo es la expresión escotista de esse diminutum referida al objeto pensado. ${ }^{24}$

Comprender la sustancia es atender al problema de los universales, una dificultad solucionada avant la lettre por Aristóteles, precisamente antes de que se plantease crudamente con Pedro Abelardo. ${ }^{25}$ Es sabido que para este lógico medieval los universales no se atribuyen a las realidades físicas, sino exclusivamente a algunas palabras. El problema de los universales se agravó o recrudeció precisamente cuando decayó el esplendor de la filosofía realista medieval tras el siglo XIII. Con ese olvido empieza nuevamente a bascular el peso de la indagación sobre lo mental y entonces prima la lógica. En esa tesitura el problema de los universales es considerado meramente como un asunto lógico (Ockham). ${ }^{26}$ El problema existe antes del apogeo de la escolástica, en el siglo XI con la dialéctica, y está después del siglo XIII, cuando los

${ }^{24}$ Cfr. D. Escoto, Distinctionum et quaestionum libri primi Sententiarum, d. XXXVI, q. Unic. Op. Om., vol. X, pp. 578 ss. Precisamente esto es lo que le reprochó Cayetano pues para él "cum esse obiectivum non sit modus essendi secundum rem, neque sit negatio, restat quod sit esse relativum secundum rationem, in communi loquedo" (In S. Th., vol. IV, p. 200).

25 "En aquella doctrina suya (de su maestro Guillermo) de la comunidad de los universales (communitas universalium) afirmaba que una cosa, esencialmente la misma, está toda a la vez en cada uno de los individuos, que serían esencialmente idénticos y sólo se distinguirían entre sí por la variedad de los accidentes. Corrigió esta doctrina suya de modo que en adelante decía que la cosa no era esencialmente (essencialiter) sino indiferentemente (indiferenter) la misma. Porque entre los dialécticos la cuestión principal de los universales radica en este punto, y es tan importante que ni siquiera Porfirio, al tratar de los universales en su Isagoge, se atrevió a definirla, diciendo: "es un problema dificilísimo" (P. Abelardo, Historia calamitatum, vol. I, p. 25).

26 "Aliter accipitur hoc nomen 'singulare' pro omni illo quod est unum et non plura, nec est natum esse signum plurium. Et sic accipiendo 'singulare' nullum 
autores se olvidan del modo cognoscitivo propio de acceso a lo real. Pero la dificultad está solucionada por Aristóteles con el descubrimiento de un principio o causa de la realidad física: la forma. Los grandes escolásticos notarán que el universal es la forma, el unum, que se da en las diversas materias, in multis. La caracterización de la materia por parte de estos pensadores como principio de individuación físico de una forma, no de formas diversas y, además, no de la forma completa, es bastante elocuente. Así, siguiendo con el ejemplo precedente, se puede decir que la forma "perro" está en cada perro, pero esa formalización de los diversos ejemplares "perrunos" no está siendo agotada en cada uno de ellos. Por eso la forma puede más que la materia, la actualiza y puede educir de ella cambios: caben variaciones reales que dan lugar a las diversas razas "perrunas" y a los diversos ejemplares de perro dentro de cada raza. La forma es una especie real. La especie perro es real, no pensada, que es la especie lógica. Ésta última no cambia, pero aquella nunca deja de cambiar merced al influjo que las causas eficientes y la final ejercen sobre ella.

Descubrir la materia y la forma es conceptualizar. Pero darse cuenta de que uno conceptualiza no es, en cambio, conceptualizar, sino que es propio del hábito conceptual. ${ }^{27}$ Darnos cuenta que concebimos no es concebir esto o lo otro, sino un hábito capaz de iluminar los diversos actos de concebir y compararlos. Hacer filosofía sobre esto es llegar tarde. Ahí vale la metáfora hegeliana referida a la filosofía, a saber, que el búho de Minerva levanta el vuelo cuando ya ha caído la tarde. En efecto, la formación y el uso del hábito conceptual es previo a cualquier tematización filosófica que sobre él se realice. El esfuerzo está en hacer una filosofía de estos asuntos que se ajuste al modo de ser de éstos, no en formar hábitos de la razón, pues éstos ya están constituidos. Sin hábito no habría acto, porque el hábito es condición de posibilidad del acto. Notar la existencia del hábito es llegar tarde. Ejercemos los hábitos y los actos, y cuando los estudiamos, la filosofía llega a deshora. Si uno

universale est singulare, quia quodlibet universale natum est esse signum plurium et natum est praedicari de pluribus. Unde vocando universale aliquid quod non est unum numero — quam acceptionem multi attribuunt universali-, dico quod nihil est universale nisi forte abuteris isto vocabulo, dicendo populum esse unum universale, quia non est unum sed multa; sed illud puerile esset" (G. de Ockham, Summa Logicae, I, c. 19).

27 "El hábito conceptual puede llamarse, simplemente, el primer hábito racional, o el concepto en tanto que trascendental" (L. Polo, Curso de teoría del conocimiento, vol. III, p. 72). Otras indicaciones del autor respecto de este hábito se encuentran en los vols. III y IV de ese curso y en sus obras El logos predicamental y El conocimiento racional de la realidad, etcétera. 
se da cuenta de que puede conceptualizar, entonces puede recuperar más de la realidad de lo que tiene visto de ella en el abstracto; es decir, puede progresar en conocimiento. Los hábitos son siempre condición de posibilidad de que los siguientes actos sean de otro nivel más alto que los que hemos ejercido hasta el momento, pues los hábitos son la perfección de la inteligencia, lo último de la potencia. ${ }^{28}$

\section{El juicio y el hábito judicativo}

¿Cuál es el siguiente acto, uno que debe ser de mayor nivel que el precedente, pero imposible sin el hábito conceptual? El acto del juicio. El juicio, dice Tomás, no solamente conoce la sustancia, es decir, la causa material y la formal, sino que también recupera el movimiento; en especial, el movimiento intrínseco de los seres vivos. El juicio es el que permite recuperar de la realidad el movimiento, y en consecuencia, el tiempo, ${ }^{29}$ porque cuando se juzga de las sustancias no sólo se dice, por ejemplo, "perro", sino que también se añade: "el perro corre", "corrió", "correrá", etc., y eso indica tiempo, movimiento. Un juicio predica accidentes respecto de sustancias, y como las acciones son accidentes, las predica respecto de compuestos hilemórficos.

Al comparar los diversos asuntos juzgados, nos damos cuenta que, en el fondo, todo aquello de la realidad a lo que los juicios se refieren está ordenado. Que unos juicios sean compatibles con otros indica que en la realidad física todo es compatible según un orden. La unidad de orden físico es la causa final. ${ }^{30}$ Siguiendo con el ejemplo precedente se puede decir que notamos que el juicio "el perro corre" es compatible con otros muchos: "el perro ladra", "el perro respira", "el perro come", etc. A su vez, captamos que todos esos juicios son compatibles con otros que predicamos del resto de la realidad física; por ejemplo: "el ladrido es sonoro", "el aire se respira", "el alimento se come", etc. Con ello se está descubriendo, en el fondo, la causa final, la superior de la realidad física.

Si en el concepto se explicitan dos causas, la material y la formal, en el juicio se descubren la eficiente y la final. Esta vía racional permite, pues, descubrir la física, la biología, la zoología, la cosmología, etc., tal como han sido clásicamente consideradas. No la física matemática, que es más propia de la vía de abstracción formal. En efecto, el sacarle partido

${ }^{28}$ Cfr. Tomás de Aquino, In III Sent., d. 23, q. 1, a. 3, a, co.; id., d. 23, q. 2, a. 3, c, co.; De Vir., a. 1, ad 1; S. Theol., I-II, q. 56, a. 1, sc.

${ }^{29}$ Cfr. id., S.C. Gentes, 1. II, cap. 96, n. 10.

30 "Finis quidem universi est aliquod bonum in ipso existens, scilicet ordo ipsius universi" (S. Theol., I, q. 103 a. 2 ad 3). 
práctico según medida a las diversas realidades es cometido de la vía de abstracción formal, por donde discurren las ciencias positivas. Pero darse cuenta de qué sea la realidad física, eso es desarrollar la física aristotélica: es el descubrimiento de que las cuatro causas lo son ad invicem, ${ }^{31}$ también es averiguar cómo esas cuatro causas están hechas vida en los seres vivos, ${ }^{32}$ qué distingue a unos seres vivos de otros en el modo de actuar en ellos las causas, etcétera.

El acto del juicio deriva de la abstracción. Si no la tuviera en cuenta, el juzgar no versaría sobre lo real físico, porque se abstrae de esa realidad, y el abstracto es intencional respecto de lo real. En el juicio se atribuyen accidentes a sustancias (i.e., el marrón a madera). Al atribuir en el juicio un accidente a una sustancia, el acto de conocer se adecua a lo real (los contenidos "marrón" y "madera" remiten a lo real). En esa adecuación se da una confrontación entre dos realidades: la física y el acto mental, pero quien confronta es el acto mental, no la realidad física (para la cual ser conocida es una denominación extrínseca). En esa confrontación es donde aparece por primera vez la verdad de modo explícito. ${ }^{33}$ Esa verdad se descubre en el mismo juicio. Lo descubre al juzgar sobre la realidad. Esa confrontación es el mismo acto de juzgar. ${ }^{34}$

Pues bien, cuando se cae en la cuenta que se ejerce el acto del juicio, acto cognoscitivo que ilumina lo real de modo adecuado, entonces se está conociendo desde el hábito judicativo o de ciencia. ${ }^{35}$ Se está conociendo la verdad o falsedad del juicio. El juicio "verdadea" la realidad, o la falsea, ${ }^{36}$ pero no conoce su propia verdad; es decir, su propio "verdadear". El juicio es la adecuación, pero también puede ser la "mentiri-

${ }^{31}$ Cfr. S. Theol., I-II, q. 1, a. 2 co.

${ }^{32}$ Cfr. S. Theol., I-II, q. 55 a. 2 ad 1.

${ }^{33}$ Como es sabido, en el concepto no se da todavía explícita la verdad, porque este acto no tiene más posibilidades que concebir la realidad física como ella es: hilemórfica. Por eso no puede tampoco falsearla. Hay una especie de adecuación en el concepto, pero no puede haber falseamiento.

${ }^{34}$ Cfr. In Peri Her., I, 3, n. 9.

35 "Al hábito de ciencia le pertenece con propiedad el recto juicio acerca de las criaturas" (S. Theol., II-II, 9, 4, co); "la ciencia responde al juicio" (In III Sent., d. 35 , q. 2, a. 4, qc. b, sc. 2); "El hábito de ciencia es el conocimiento habitual que sigue al juicio, o que se adquiere en tanto que se juzga" (L. Polo, Curso de teoría del conocimiento, vol. III, p. 71). Otras indicaciones respecto de este hábito en dicho autor se encuentran en sus vols. III, IV y V de ese curso; cfr., asimismo, El logos predicamental.

36 "Afirmar en falso es una precipitación: un dejar en suspenso el hábito judicativo y la tercera operación racional" (L. Polo, Curso de teoría del conocimiento, vol. IV, p. 101, n. 56).

Diánoia, vol. LIII, no. 61 (noviembre 2008). 
ficación". ${ }^{37} \mathrm{El}$ acto de juzgar puede aunar las cosas o descomponerlas, según están o no aunadas o separadas en la realidad. El juicio, dice Tomás, compone y divide las cosas según están en la realidad. ${ }^{38}$ Esa composición y división es la adecuación misma, el notar que eso es así en la realidad. Si se adecua, verifica, esclarece. Pero conocer el acto del juicio no es propio del acto del juicio. Darse cuenta de que "verificamos" o "mentirificamos" la realidad física es propio del hábito judicativo. ${ }^{39}$

Por el contrario, en los juicios lógicos, al no tener en cuenta que son accidentes y sustancias reales las que se predican, sino objetos exclusivamente mentales, es decir, formas o conceptos mentales, se puede aunar o separar lo que se quiera (por ejemplo, "color violeta" con "caballo"). Se pueden redactar las novelas que se deseen, y no pasa nada. Para su verdad, basta que guarden una coherencia interna; es decir, que no se contradigan unas partes con otras (así procede, en rigor, la filosofía modal). También cabe mirar lo descubierto en la realidad como asuntos lógicos, no como reales. Con todo, también es claro en la vertiente lógica de nuestro pensar que una cosa es juzgar y otra darse cuenta de que se juzga. Lo segundo permite dirimir qué juicios lógicos son verdaderos y cuáles son falsos. Ese darse cuenta también será posible merced a un hábito: el del juicio lógico. Éste se distingue del llamado por el de Aquino de ciencia. ${ }^{40}$ En ambos casos, darse cuenta de que uno juzga con verdad o con falsedad no es un juicio, sino un hábito judicativo.

El hábito judicativo es la condición de posibilidad de que se puedan hacer juicios, aunque sean falsos, pero también permite darse cuenta de que se está juzgando de modo falso; es decir, mediante tal hábito no sólo conocemos la verdad de los juicios, sino también su error. En cualquier caso, el hábito ilumina los actos de juzgar, no los objetos pensados. ${ }^{41}$ La verdad descubierta por el juicio racional versa sobre la

${ }^{37}$ Cfr. E. Alarcón, "El debate sobre la verdad", pp. 35-62.

${ }^{38}$ Cfr. S. Theol., I, q. 89 a. 5 co.; In III Sent., d. 23 q. 2 a. 2 qc. 1 co.; De Ver., q. 14 a. 1 co., etcétera.

39 "In speculativis demonstrativa scientia dicitur iudicativa inquantum per resolutionem in prima principia intelligibilia de veritate inquisitorum diiudicatur. Et ideo consideratio maxima pertinet ad iudicium" (S.Theol., II-II, q. 53, a. 4 co.).

${ }^{40}$ Cfr. respecto del hábito de ciencia: J.J. Sanguineti, Ciencia aristotélica y ciencia moderna; La filosofía de la ciencia según Sto. Tomás; O. Hoenen, "De origine principiorum scientiae", pp. 153-184.

${ }^{41}$ Ramírez piensa que el hábito de ciencia "no es otra cosa que las especies inteligibles, habitualmente conservadas en el intelecto posible" (op. cit., p. 249). Urdánoz es de parecer diverso, pues considera que "el hábito no se identifica con las especies, sino que es una perfección de la potencia distinta de ellas" (Tratado de los hábitos y virtudes, p. 46). Y más adelante añade: "Los hábitos intelectuales no se 
realidad física; la del juicio lógico, en cambio, sobre los objetos mentales sobre los que se opera, o sobre lo que se está inventando. Pero el darse cuenta de la verdad o falsedad del propio acto de juzgar no versa sobre la realidad, o sobre los objetos mentales, sino sobre el acto del juicio que se está ejerciendo, sobre el acto de pensar que se materializa, al manifestarlo en lenguaje, en proposiciones. Por lo tanto, no es lo mismo la verdad que dice el juicio, ${ }^{42}$ que la verdad que versa sobre el juicio. Por lo demás, más que decir de un juicio que éste acierta, o de otro que éste se equivoca, en rigor, es más pertinente decir que quien acierta o se equivoca es la persona que juzga. Ahora bien, la persona se puede dar cuenta de que con sus juicios acierta o se equivoca merced al hábito judicativo. Precisamente por disponer de ese hábito uno puede ser responsable de sus juicios.

El hábito de ciencia no es un juicio, porque es un manifestar los actos de juzgar, y eso es más alto que juzgar. Un juicio juzga acerca de la realidad física, no directamente acerca de otros actos mentales que son inferiores a él. Tampoco se juzga a sí mismo o a asuntos más altos que el propio juicio. Una cosa es conocer asuntos reales extramentales, y otra conocer que se juzga, que es conocer una realidad superior, porque juzgar es un acto inmaterial y, por tanto, más real que la realidad física juzgada. ${ }^{43}$ En efecto, es más acto, más perfecto. Aquella, la realidad física, no puede ser acto porque es movimiento. El hábito judicativo es más que un juicio. Es un acto, pero es más acto que las operaciones inmanentes, porque puede con ellas, es decir, las conoce o manifiesta. El hábito es más perfecto que el acto como operación inmanente. Tanto el juicio como su hábito son inmanentes. Pero ¿cómo notar que uno es más perfecto que el otro? Porque uno conoce al otro y no al revés. El hábito es más bien intuitivo, experiencial, más íntimo a uno que los actos, más vital. Funciona, por así expresarlo, con un golpe de vista. No tiene que ver con composiciones. El juicio compone y divide. El hábito

han de identificar con las especies o noticias adquiridas, conservadas habitualmente en el intelecto" (id., p. 50).

42 "La verdad del intelecto es la adecuación del intelecto y la realidad, según que el intelecto dice ser lo que es, o no ser lo que no es. La verdad en el intelecto pertenece a aquello que el intelecto dice, no a la operación por la cual dice aquello" (S.C. Gentes, 1. I, cap. 59, n. 2).

43 "Es patente que el mismo inteligir no puede ser el primer objeto del intelecto" (In IV Sent., d. 49, q. 1, a. 1, qc. b, co.). Y en otros lugares añade: "La referencia de la potencia a algún objeto es previa a la referencia sobre su acto" (Quodl., VIII, q. 9, a. 1 co.); "aunque la razón de verdad quede perfecta en el acto del intelecto, y tenga el fundamento en el mismo ser de la cosa; el juicio sobre la verdad sigue al juicio sobre el ser de la cosa y sobre el intelecto" (In I Sent., d. 19, q. 5, a. 3 co).

Diánoia, vol. LIII, no. 61 (noviembre 2008). 
judicativo ni compone ni divide, sino que discierne statim entre juicios verdaderos y juicios falsos.

\section{La "demonstratio" y su hábito}

La razón teórica, aparte del concebir y juzgar, dispone de otro acto que Tomás de Aquino llama demostración o raciocinio, distinto del silogismo, que es formal y trabaja con entes de razón. La asimilación de la demostración al silogismo es frecuente en la mayor parte de los comentadores aristotélicos. El silogismo lógico es un invento del Estagirita con poca referencia a lo real. Hay que distinguirlo de lo que Tomás de Aquino llama demostración, de la cual distingue dos tipos: la propter quid y la quia. La primera procede analizando, y la otra, de los efectos a la causa. Ni una ni otra demostración que describe Sto. Tomás es una búsqueda del fundamento real, es decir, de por qué las cuatro causas existen. Juega con las causas, y saca a relucir alguna de ellas; pero no desentraña el fundamento de ellas.

Después del juicio y del hábito correspondiente queda algo por desentrañar de la realidad; hay algo por esclarecer. En efecto, descubiertas las cuatro causas, uno se da cuenta de que ninguna de ellas es fundamento o principio de las demás. Todas tienen que ver con todas hasta tal punto que ninguna se puede desligar de las otras, ni se pueden entender por separado, pues - como se ha adelantado- son causas ad invicem. Ni la causa material es fundamento de la formal, ni la formal es razón de que la material exista, y así todas. Son concausas, sí, pues no pueden darse aisladamente. Aunque una sea más causa que la otra, porque actúa sobre la otra, no puede desligarse de ella y es irreductible a ella. Existe una superior a las demás, que actúa sobre ellas atrayéndolas: la causa final u orden del universo. Por eso las realidades físicas (al margen de la intervención negativa humana) cambian siempre a mejor (primero existen sólo seres inertes, luego vida vegetativa, más tarde sensitiva...). Pero tampoco la causa final da razón ninguna ni de sí misma ni de las demás.

El juicio se agota con el descubrimiento de la tetracausalidad. Lo que es físico, ${ }^{44}$ que es de donde se abstrae, no puede dar a conocer ningún principio más allá de las cuatro causas. Abstrayendo de lo físico se conoce el qué de la realidad física, pero no el por qué. Sin embargo, las causas deben responder a un por qué, o sea, a un fundamento. El

\footnotetext{
44 "Físico" no es sólo material, puesto que indica también formal, eficiente y orden universal.
} 
intento de fundamentar corresponde a la última operación de la razón, a la que se puede llamar, por este motivo, fundamentación. ${ }^{45}$ Se trata de buscar lo implícito que queda por buscar en lo que se ha descubierto hasta ahora de la realidad física. La pregunta acerca del fundamento es el intento de demostrar lo que subyace, pero no se puede acceder a él con operaciones mentales derivadas de la abstracción, porque el fundamento no es físico. Este límite supone el agotamiento de la razón en su operatividad que versa sobre la realidad física. Dar con el fundamento es imposible sin sobrepasar ese nivel racional, sin saltar de nivel. ${ }^{46} \mathrm{El}$ esclarecimiento del fundamento se da en un conocer superior, no argumentativo, en un conocer distinto de la ratio, al que Tomás de Aquino llama intellectus. ${ }^{47}$

Ahora bien, una cosa es el intento de demostrar (demonstratio), y otra notar que se está operando de esa manera. Esto último es un hábito que versa sobre los actos de fundamentar. Este hábito se puede llamar de los principios lógicos, pues conoce que todos los actos de demostrar se pueden reducir a unos pocos que se presentan entrelazados. En efecto, uno de ellos se puede llamar de identidad, y se suele formular objetivamente así: " $A$ es $A$ ". Otro es el de contradicción, y se expresa: "A no es no A". Cabe un tercero, al que se puede llamar de causalidad, que se puede enunciar: "no hay efecto sin causa" (o "la causa es siempre causa de efecto"). Se dan entrelazados porque unos no se pueden dar sin los otros, por ejemplo, el primero sin el segundo: " $A$ es $A$, porque $A$ no es no $A$ ". Pues bien, presentadas someramente las tres operaciones racionales y sus hábitos correspondientes, cabe ahora pasar a detener la atención en la primera operación racional, el concepto, y en su hábito correspondiente, el conceptual.

\section{5. "Conceptus" o "verbum mentis" y "locutio" o "vox"}

Lo primero que hay que tener en cuenta en este punto es la siguiente precisión terminológica: para Tomás de Aquino, concepto y verbo son

45 “Si afirmo que 'A es' todavía no sé por qué es: eso queda implícito. La operación que hace explícito el implícito de la afirmación es el fundar (la llamo operación de fundar porque es la operación por la que se conoce el fundamento)" (L. Polo, Curso de teoría del conocimiento, vol. III, p. 71).

${ }^{46}$ A ese salto Tomás de Aquino lo denomina separatio. Cfr. In Boet. De Trin., 3, 5, 3 , co., 5 .

${ }^{47}$ Cfr. J. Peghaire, Intellectus et ratio selon S. Thomas D'Aquin; J. Cruz, Intelecto y razón. Las coordenadas del pensamiento clásico; P. Moya, El principio del conocimiento; S. Ramírez, Utrum aliquis habitus sit a natura, Op. Om.

Diánoia, vol. LIII, no. 61 (noviembre 2008). 
sinónimos. ${ }^{48}$ Un texto del siglo XIII perteneciente a un autor desconocido, que sigue en este extremo a San Agustín, le da también las denominaciones de conceptum mentis o verbum cordis. ${ }^{49}$ Tomás conoce la procedencia agustiniana de esas denominaciones, ${ }^{50}$ y las usa alguna vez. ${ }^{51}$ Otras, lo considera como sinónimo de intentio intellecta. ${ }^{52}$ Explica que la distinción entre esas denominaciones se debe a que cuando se usa concepto, se le considera tal como está en la mente, mientras que cuando se usa verbo, se le considera en tanto que puede ser comunicado por medio de la palabra. ${ }^{53}$ Interesa no confundir lo concebido - a lo que

48 "Intellectus autem dicendo, generat verbum, quod est conceptus eius" (Super $H e b$., cap. 1, lec. 3). En esa misma obra antes ha escrito: "verumtamen proprie loquendo, verbum non dicitur nisi quod procedit ut conceptus ab intellectu, ad quod sequitur procedere in similitudinem speciei" (Super Heb. cap. 1. lec. 2). Y más explícitamente: "verbum significat conceptum intellectus" (S. Theol., I, q. 34, a. 1 , co.).

49 "Et subdit ibi Augustinus, quod cogitatio hominis in corde formata, quae dicitur conceptus mentis, est verbum cordis, quod neque Graecum, neque Latinum, neque cujuscumque alterius linguae est: et addit, quod verbum, quod foris fit, idest quod foris sonat, est signum verbi quod intus latet, cui magis competit nomen verbi: nam quod ore carnis profertur, vox est verbi" (Ignotus Auctor, De sacramento Eucharistiae, cap. 8).

50 "Si ergo accipiatur locutio secundum quod est in parte intellectiva tantum, sic est verbum cordis, quod etiam ab aliis dicitur verbum rei, quia est immediata similitudo ipsius rei; et a Damasceno dicitur, quod est naturalis intellectus motus, velut lux ejus et splendor; et ab Augustino dicitur verbum animae impressum. Secundum autem quod est in imaginatione, quando scilicet quis imaginatur voces quibus intellectus conceptum proferre valeat, sic est verbum quod habet imaginem vocis, et quod ab aliis dicitur verbum speciei vocis, et a Damasceno dicitur verbum in corde enuntiatum, et ab Augustino dicitur verbum animi sinu cogitatum. Secundum autem quod iam est in corporali actione per motum linguae et aliorum instrumentorum corporalium, dicitur verbum vocis" (In I Sent., d. 27, q. 2, a. 1 , co.).

51 "Est autem intellectus noster aliquando quidem in potentia intelligens, aliquando vero in actu. Quandocumque autem actu intelligit, quoddam intelligibile format, quod est quasi quaedam proles ipsius, unde et mentis conceptus nominatur. Et hoc quidem est quod exteriori voce significatur: unde sicut vox significans, verbum exterius dicitur, ita interior mentis conceptus verbo exteriori significatus, dicitur verbum intellectus, seu mentis" (De rationibus fidei, cap. 3 co.). Cfr. también: Super Iob, cap. 1.

52 "Intellectui nostro accedit ex tempore verbum interius conceptum, quod est intentio intellecta" (S.C. Gentes, lib. IV, cap. 11, n. 10).

53 "Species ergo conceptae interius, secundum quod manent in simplici conceptione intellectus, habent rationem intelligibilis tantum: secundum autem quod ordinantur ab intelligente ut manifestandae alteri, habent rationem verbi, quod dicitur verbum cordis" (In II Sent., lib. 2 d. 11 q. 2 a. 3 co.); "Dicitur verbum vox exterior, 
aquí atendemos - con el acto de concebir, al que Tomás llama simple aprehensión, ${ }^{54}$ y que otros hacen equivaler a la receptio, ${ }^{55}$ término equívoco para el de Aquino, pues - siguiendo a Aristóteles- considera que el conocer siempre es activo, y sólo comparativamente con la realidad física se puede decir que es "cierto padecer".

Lo siguiente para tener en cuenta es que Tomás de Aquino no se cansa de marcar en este punto una neta distinción jerárquica entre pensamiento y lenguaje, pues para él una cosa es el concepto de la mente y otra inferior su manifestación lingüística por medio de la palabra, ${ }^{56}$

quia significat interiorem mentis conceptum" (S. Theol., I, q. 34, a. 1, co.). Cfr. también: S.C. Gentes, lib. IV, cap. 13, n. 5; Super Io., cap. I, lec. 1.

${ }^{54}$ En cuanto a la terminología, a la primera operación racional o de la vía de abstracción total se le suele denominar "simple inteligencia" (simplex intelligentia; cfr. S. Theol., II-II, q. 153, a. 5 co.), "simple aprehensión" (simplex aprehensio; cfr. In II Sent., d. 24, q. 3, a. 1co.; De Ver. q. 24, a. 5, ad 4; In De Anima. L. III, 12, n. 3), "decir" (dicere. Cfr. S. Theol., I, q. 27, a. 1co), "inteligencia de los indivisibles" (intelligentia indivisibiliun; cfr. Quodl. V, q. 5, a. 2 co.), "verbo" (verbum; cfr. In I Sent., d. 27, q. 2, a. 2, qc. a co.; S. C. Gentes, 1. IV, cap. 19, n. 8; Quodl. V, q. 2, a. 1 ad; S. Theol., I, q. 27, a.1 co.; id., q. 34, a.1 co.; id., q. 107, a. 1 co), "verbo del corazón" (verbum cordis; cfr. Quodl. V, q. 5, a. 2 co.), "conceptualización” (conceptio; cfr. De Ver., q. 4, a. 2 co.; S. Theol., I, q. 27, a. 1 co), "definición" (definitio; cfr. Quodl., V, q. 5, a. 2co), e incluso con el término genérico de "inteligir" (inteligere; cfr. In I Sent., d. 27, q. 2, q. 2, qc. a, co.; De Malo, q. 15, a. 4 co.), etc., o simplemente como "un modo de abstracción" (modum abstractionis). Tomás de Aquino usa una misma palabra para designar el acto y lo conocido, es decir, la concepción y lo concebido. En consecuencia, en el concepto hay que diferenciar el acto que concibe de lo concebido, y a su vez, lo concebido hay que distinguirlo de las especies y también de lo real. Tenemos, según Tomás de Aquino, cuatro asuntos distintos en este nivel cognoscitivo: el acto de concebir, lo concebido por el acto, las especies, que son el objeto de la abstracción, y la realidad física de la que se concibe: "el que intelige en el inteligir puede referirse a cuatro cosas: a saber, a la realidad que se intelige, a la especie inteligible, por la que se hace el intelecto en acto, a su inteligir, y a la concepción del intelecto" (De Pot., q. 8, a.1 co.).

${ }^{55}$ Cfr. B. Garceau, Judicium, vocabulaire, sources, doctrine de Saint Tomás d'Aquin, p. 35. Para Lonergan, cabe hablar de una "operatio receptiva" (op. cit., p. 139); "pour autant que le acte inmanent est une perfection reçue dans une créature, il est nécessariement un pati" (id., p. 141). Pero estimo que estas expresiones no son correctas.

56 "In nobis enim locutio dicitur ipsa manifestatio interioris verbi quod mente concipimus" (De Ver., q. 9 a. 4 co.). Cfr. también: Super Iob, cap. 6; S. Theol., I, q. 34, a. 1, ad 1; In Peryher., lib. I, lec. 2 n. 6; Super I Cor., cap. 13 vs. 3. En otros lugares señala: "labiis enim formantur voces exterius quibus interiores conceptus cordis exprimimos" (Super Iob., cap. 11); "vox enim expressiva est interioris conceptus" (id., cap. 5, lec. 4). Y en otro lugar dice: "nomen alicuius rei nominatae a nobis dupliciter potest accipi, quia vel est expressivum, aut significativum conceptus

Diánoia, vol. LIII, no. 61 (noviembre 2008). 
que obviamente puede ser oral o escrita. ${ }^{57}$ La conveniencia de esa manifestación externa se debe - según él- a que, dado que nuestra inteligencia toma sus objetos de los sentidos, es oportuno que exprese sus conceptos de modo sensible. ${ }^{58}$ La palabra deriva del concepto, ${ }^{59}$ no al revés, siendo éste la condición de posibilidad de aquélla, no a la inversa. En efecto, la palabra depende del verbum mentis. ${ }^{60} \mathrm{El}$ concepto es primero, la palabra viene después ${ }^{61} \mathrm{y}$, además, no de modo necesario. ${ }^{62}$ Aquél no es, en sentido propio, efecto ninguno, pero la palabra sí lo es. ${ }^{63}$ El uno es silencioso; la otra, sonora. ${ }^{64} \mathrm{El}$ primero es inmaterial, mientras que la segunda es sensible. ${ }^{65} \mathrm{El}$ concepto es natural, mientras que la palabra es convencional, ${ }^{66}$ y lo es porque las cosas que se realizan hacia el exterior no están exclusivamente reguladas por la in-

intellectus, quia voces sunt notae, vel signa passionum, vel conceptuum qui sunt in anima" (Super Eph., cap. 3 1. 4).

57 "Unus homo alteri manifestat explicando conceptum suum per aliqua signa exteriora, puta per vocem vel scripturam" (Super Rom., cap. I, lec. 6).

58 "Sed quia intellectus noster a sensibilibus naturaliter accipit, oportet quod ad interiores conceptus exprimendos quaedam sensibilia signa aptentur, quibus cogitationes cordium nobis manifestentur" (De Ver., q. 9 a. 4 co.).

59 "Verbum vocale est quoddam effatum interioris conceptus" (In I Sent., d. 39, q. 2 , a. 1 , ad 5).

60 "Dicere importat principaliter habitudinem ad verbum conceptum nihil enim est aliud dicere quam proferre verbum. Sed mediante verbo importat habitudinem ad rem intellectam, quae in verbo prolato manifestatur intelligenti" (S. Theol., I, q. 34 a. 1 ad 3).

61 "Vox origine posterior est verbo, sed notitia prior. Nam verbum in corde conceptum, per vocem prolatam cognoscimus, cum sit signum eius" (Super Io., cap. I, lec. 12); "Tria requiruntur ad locutionem nostram. Primo, verbi conceptio, qua scilicet praeconcipiatur in mente id quod ore loquendum est; secundo ipsius verbi concepti expressio, qua insinuetur quod conceptum est; tertio ipsius rei expressae manifestatio, qua res expressa evidens fiat" (Super Heb. cap. I, lec. 1).

${ }^{62}$ En efecto, por eso, "nullus autem cognoscit verbum dum est in corde hominis, nisi ille qui concipit; sed tunc primo cognoscitur cum profertur" (In Symbolum Apostolorum, a. 3 co.).

63 "Vox nostra est effectus verbi concepti in mente nostra" (Super Io., cap. I, lec. 5).

64 "Manifestum est enim, quod conceptio cordis vel intellectus absque voce est cum silentio, sed per sensibiles voces, illud silentium cordis enuntiatur" (In De Div. Nom., cap. 4, lec. 1).

65 "Verbum nostrum in mente conceptum invisibile est, exterius autem voce prolatum sensibile fit" (S.C. Gentes, lib. 4 cap. 46, n. 2). Cfr. también: In II Sent., lib. 2 d. 11 q. 2 a. 3 co.

66 "Significare conceptus suos est homini naturale, sed determinatio signorum est secundum humanum placitum" ( $S$. Theol., II-II, q. 85, a. 1, ad 3). Y en otra 
teligencia, sino que también interviene la voluntad. ${ }^{67}$ El primero —para Tomás- es puramente intencional, con una intencionalidad de semejan$z a,{ }^{68}$ mientras que el lenguaje no tiene una intencionalidad pura, sino derivada, mixta.

Por otro lado, como es conocido, la semejanza del concepto — según Tomás- puede ser doble, ya se trate del fruto de la razón teórica o de la práctica: "el verbo concebido en el intelecto es imagen o ejemplar de la sustancia de la realidad entendida". ${ }^{69}$ En efecto, en la razón práctica las formas artificiales se parecen al ejemplar en la mente del artista, ${ }^{70}$ mientras que en el conocimiento de la naturaleza, es el concepto de quien investiga el que se asemeja a la realidad física. ${ }^{71}$ No es que el de Aquino tenga nada contra la palabra (máxime cuando escribió tanto en tan pocos años), sino que, aun considerándola muy importante, es más, la más importante de las realidades sensibles, ${ }^{72}$ con todo, afirma que es segunda respecto del concepto de la inteligencia. Para él, la palabra está a medio camino entre el concepto de la mente y las obras humanas externas. ${ }^{73}$ Depende del concepto, y de ella dependen las acciones, pues

parte añade: "homines communius et expressius suos conceptus significare consueverunt" (Quod., I, q. 6, a. 1, co.).

67 "Artifex autem per verbum in intellectu conceptum, et per amorem suae voluntatis ad aliquid relatum, operator" (S. Theol., I, q. 45 a. 6 co.).

68 "Verbum autem mentis nostrae est, quando formamus actu formam rei cuius notitiam habemus, et hoc significamus verbo exteriori. Et hoc verbum sic conceptum est quaedam rei similitudo quam in mente tenemus, et simile secundum speciem" (Super Col., cap. I, lec. 4); "verbum semper est ratio et similitudo rei intellectae" (Super Io., cap. I, lec. 1). "Verbum autem interius conceptum est quaedam ratio et similitudo rei intellectae" (S.C. Gentes, lib. IV, cap. 11, n. 14).

${ }^{69}$ S.C. Gentes, lib. IV, cap. 11, n. 15.

70 "Quia verbum artificis, idest conceptus eius, est similitudo exemplaris eorum quae ab artifice fiunt" S. Theol., III, q. 3, a. 8, co.). Cfr. también: Super Heb., cap. XI, lec. 2. S. Theol., I, q. 33, a. 3, ad 1; id., q. 44, a. 3, co.

71 "Ratio intellectus divini aliter se habet ad res quam ratio intellectus humani. Intellectus enim humanus est mensuratus a rebus, ut scilicet conceptus hominis non sit verus propter seipsum, sed dicitur verus ex hoc quod consonat rebus" (S. Theol., I-II, q. 93, a. 1, ad 3).

72 "Si vero intantum procedat talis aggravatio, ut etiam exteriora membra immobilitet ab opere, quod pertinet ad acediam; sic erit extraneum quantum ad utrumque, quia nec est fuga, nec est in appetitu. Ideo autem specialiter acedia dicitur vocem amputare, quia vox inter omnes exteriores motus magis exprimit interiorem conceptum et affectum, non solum in hominibus, sed etiam in aliis animalibus, ut dicitur in I Polit" (S. Theol., I-II, q. 35, a. 8, co.).

${ }^{73}$ Cfr. S. Theol., I-II, q. 72, a. 7, co.

Diánoia, vol. LIII, no. 61 (noviembre 2008). 
es claro que sin ella no cabe ni sociedad, ${ }^{74}$ ni enseñanza ninguna, ${ }^{75}$ ni, por ende, trabajo humano.

Las precedentes distinciones son interesantes, sobre todo teniendo en cuenta que parte de la filosofía analítica y el pragmatismo de nuestra época parecen haberlas olvidado. Pero Tomás es muy claro al respecto: "locutio autem est signum audibile interioris conceptus". ${ }^{76}$ La voz, la palabra, el lenguaje en definitiva, es signo del concepto, instrumento suyo, pero no es el concepto, que es lo principal. Por eso, la palabra no puede reflejar bien lo pensado, sino sólo interpretarlo en cierto modo. ${ }^{77}$ Tomás está de acuerdo con Agustín de Hipona en que las palabras se forman para significar los diversos conceptos de la mente, ${ }^{78}$ no a la inversa; $y$ también concuerda con Aristóteles, pues como él mismo confiesa, esta tesis es propia del Estagirita. ${ }^{79}$ Además, para corroborar su posición, pone un ejemplo muy concreto (dicho sea de paso, las mencionadas tendencias filosóficas actuales gustan de la ejemplificación), a saber, "la voz que no es significativa no se puede llamar verbo. Por tanto, el verbo se dice voz exterior porque significa el concepto interior de la mente". 80 En este ejemplo se nota claramente la dependencia y subordinación de las palabras respecto de los conceptos. Por su parte, los conceptos lo son de la realidad física, pues si no existiesen sustancias no seríamos capa-

74 "Est igitur necessarium homini quod in multitudine vivat, ut unus ab alio adiuvetur et diversi diversis inveniendis per rationem occupentur, puta, unus in medicina, alius in hoc, alius in alio. Hoc etiam evidentissime declaratur per hoc, quod est proprium hominis locutione uti, per quam unus homo aliis suum conceptum totaliter potest exprimere" (De regno, lib. I, cap. 1, co.).

75 "In tantum enim ad sapientem vel scientem pertinet posse docere, in quantum potest interiorem conceptum verbis exprimere" (S. Theol., II-II, q. 181, a. 3, ad 2).

${ }^{76}$ S. Theol., II-II, q. 181, a. 3, co.

77 "Instrumentum autem eius est oratio, quia per orationem virtus interpretativa interpretatur mentis conceptum: hoc enim dicimus instrumentum, quo agens operatur" (In Peryher., lib. I, lec. 6, n. 7).

78 "Dicit autem Augustinus, in II de Doct. Christ. quod verba inter homines obtinuerunt principatum significandi, quia verba diversimode formari possunt ad significandos diversos conceptus mentis, et propter hoc per verba magis distincte possumus exprimere quod mente concipimus" (S. Theol., III, q. 60, a. 6 co.).

79 "Quod quidem ab interiori procedit quantum ad duo quae in verbo exteriori inveniuntur, scilicet vox ipsa, et significatio vocis. Vox enim significat intellectus conceptum, secundum philosophum, in libro I Periher. et iterum vox ex imaginatione procedit, ut in libro De Anima dicitur. Vox autem quae non est significativa, verbum dici non potest" ( $S$. Theol., I, q. 34, a. 1 co.).

80 "Vox autem quae non est significativa, verbum dici non potest. Ex hoc ergo dicitur verbum vox exterior, quia significat interiorem mentis conceptum" ( $S$. Theol., I, q. 34, a. 1, co.). 
ces de concebirlas. En contraposición con esta tesis tomista, el análisis lingüístico reciente de corte pragmático tiende a hacer girar tanto la realidad como el pensamiento en torno al lenguaje, no a la inversa.

Tomás de Aquino observa algo todavía más agudo que pasa también desapercibido a las mencionadas corrientes de pensamiento; a saber, que lo que expresa la voz es lo concebido, no el acto de concebir, ni el habito de la inteligencia, ni la propia potencia intelectual. ${ }^{81}$ Por eso, mediante el análisis del lenguaje estas realidades son inasequibles, y es claro que ellas son más importantes que las realidades físicas y lingüísticas. Por lo demás (y es tesis opuesta a la hegeliana), Tomás de Aquino afirma la conveniencia de la pluralidad de los conceptos, sencillamente porque nuestro conocimiento no es simple o divino. ${ }^{82}$ Además, si los conceptos en nosotros se multiplican, mucho más las palabras, porque ninguna de ellas expresa completamente el concepto. ${ }^{83}$ En efecto, basta observar la cantidad de palabras presentes en los diversos idiomas para designar un mismo concepto. Además, dentro de un mismo idioma, hay varios tipos de palabras para referirse a un mismo concepto. ${ }^{84}$

\section{El hábito conceptual}

Abordemos a continuación el punto que más nos interesa: el hábito conceptual. Pero previamente recordemos que para Tomás de Aquino lo concebido deriva del acto concebir. ${ }^{85}$ En efecto, "el verbo que se concibe

81 "Sic ab intellectu conceptum dicitur verbum interius, hoc enim est quod significatur per vocem; non enim vox exterior significat ipsum intellectum, aut formam ipsius intelligibilem, aut ipsum intelligere, sed conceptum intellectus quo mediante significat rem" (De Pot., q. 9, a. 5, co.).

82 "Scimus enim primo quod in Deo est tantum unum intelligere, non multiplex sicut in nobis: aliud enim est intelligere nostrum quo intelligimus lapidem et quo intelligimus plantam; sed unum est Dei intelligere, quo Deus intelligit et se et omnia alia. Et ideo intellectus noster concipit multa verba, sed verbum conceptum a Deo est unum tantum. Iterum intellectus noster imperfecte plerumque intelligit et seipsum et alia; intelligere autem divinum non potest esse imperfectum" (De Pot., q. 9, a. 5 co.). Cfr. también: De rationibus fidei, cap. 3 S.C. Gentes, lib. I, cap. 35, n. 2.

83 "Nam et homo, cum mentis conceptum uno vocali verbo videt sufficienter exprimi non posse, verba diversimode multiplicat ad exprimendam per diversa suae mentis conceptionem" (S.C. Gentes, lib. III, cap. 97, n. 2).

${ }^{84}$ Sirva como ejemplo de esta tesis el lenguaje inglés, que para expresar multiplicidad de conceptos usa dos tipos de palabras, unas derivadas de raíz latina y otras derivadas de raíz germánica.

85 "Est autem duplex operatio intellectus, secundum Philosophum in III De Anima. Una quidem quae vocatur indivisibilium intelligentia, per quam intellectus format in seipso definitionem, vel conceptum alicuius incomplexi. Alia autem operatio

Diánoia, vol. LIII, no. 61 (noviembre 2008). 
en nuestra mente no sale de la potencia al acto a menos que nuestro intelecto proceda de la potencia al acto. Pues el verbo no nace de nuestro intelecto sino en cuanto que existe en acto. Pero cuando existe en acto, se da en él el verbo concebido" ${ }^{86}$ Como se ha indicado, en este acto no se da todavía la verdad, porque con él todavía no se afirma si lo concebido es o no es así en la realidad física, asunto que ejerce el juicio. ${ }^{87}$ Recuérdese también que, para Tomás, el juicio compara conceptos. $^{88}$

Por otro lado, como según Tomás de Aquino los actos u operaciones inmanentes proceden de los hábitos, ${ }^{89}$ el acto de concebir debe proceder de un hábito al que, siguiendo el nombre dado al acto, podemos denominar conceptual. Ahora bien, ¿alude Tomás en sus escritos a este hábito? Rastreemos algunos textos pertinentes. En uno se declara que "cuando la mente se convierte a su acto considerando lo que está claro en hábito, alguien se habla a sí mismo, pero ese concepto de la mente se denomina verbo interior". ${ }^{90}$ En el texto se defiende de modo claro que el hábito es previo al acto. También se manifiesta que del acto del que se habla es el concebir. Pero no se dice explícitamente que el acto de concebir surja del hábito conceptual. ¿Puede surgir de otro hábito, o de la mente en general? Para elucidar esta cuestión es pertinente atender a más pasajes.

En otro texto se indica que "el hábito y el acto comunican en el objeto. Y por eso es manifiesto que aquella razón procede por parte de la materia del concepto interior". ${ }^{91}$ Aquí se alude explícitamente a lo concebido por el concepto. Y previamente se dice que el hábito y el acto comunican en el objeto concebido. ¿Se trata del hábito conceptual?

est intellectus componentis et dividentis, secundum quam format enuntiationem" (Quodl., V, q. 5, a. 2 co.).

${ }^{86}$ S.C. Gentes, lib. IV, cap. 14 , n. 3.

87 "Conceptus... non est verum vel falsum, nisi quando additur esse vel non esse, per quae exprimitur iudicium intellectus. Potest autem addi esse vel non esse, vel secundum praesens tempus, quod est esse vel non esse in actu, et ideo hoc dicitur esse simpliciter; vel secundum tempus praeteritum, aut futurum, quod non est esse simpliciter, sed secundum quid; ut cum dicitur aliquid fuisse vel futurum esse" (In Peryher., lib. I, lec. 3, n. 13).

${ }^{88}$ Cfr. In Peryher., lib. I, lec. 3, n. 4.

89 "In nobis omnes habitus per actus manifestantur" (S.C. Gentes, lib. IV, cap. 12, n. 4).

${ }^{90}$ S. Theol., I, q. 107, a. 1, co. Cfr. M.J. O'Connell, "St. Thomas and the verbum: An Interpretation", pp. 224-234; W.W. Meissner, "Some Aspects of the verbum in the Texts of St. Thomas", pp. 1-30.

${ }^{91}$ S. Theol., II-II, q. 181, a. 3, ad 2. 
Parece, pero no se dice taxativamente que el acto de concebir surja del hábito conceptual. Probemos más posibilidades documentales. En otro libro escribe que

según el intelecto, al principio el hombre no es apto instantáneamente para formar conceptos inteligibles, sino después cuando llega al estado de perfección. No siempre entiende en acto, sino que primero es sólo potencia intelectiva, y después se hace inteligente en acto, y cuando deja de entender en acto, permanece inteligente en potencia o sólo en hábito. ${ }^{92}$

También aquí se alude manifiestamente a los conceptos. Respecto de ellos, que parecen ser el fin del conocimiento, se dice que la inteligencia puede estar en tres estados: en potencia, en hábito o en acto, siendo el tercero, para Tomás, su estado más perfecto. Cuando éste remite, se pasa de nuevo al estado de potencia o al de hábito. Aquí se nos indica el paso del estado de acto al de hábito en cuanto al conocimiento de conceptos se refiere, pero no a la inversa.

Incrementemos, pues, la base textual. En otro lugar Tomás escribe que "en el alma humana... el verbo concebido interior procede de la memoria". ${ }^{93}$ Los hábitos son la memoria intelectual. De acuerdo con esa tesis, este escrito manifiesta que de los hábitos surge el verbo concebido interiormente. Pero no se dice que ese hábito sea el conceptual y tampoco que de tal memoria proceda el acto de concebir. Semejante a este texto es otro en el que se lee:

el inteligible está en el intelecto de triple modo, primero sin duda, habitualmente, o según la memoria, como dice Agustín; segundo, como en acto considerado o concebido; tercero, como referido a otro. Es manifiesto que el inteligible pasa del primer grado al segundo por el imperio de la voluntad, por lo que en la definición de hábito se dice por lo que el que usa cuando quiere. ${ }^{94}$

Aquí se alude a que el concepto puede estar en hábito o en acto, y que el paso del uno al otro lo rige la voluntad. De manera que — según Tomás de Aquino- al fin debemos recurrir a la voluntad para saber si nuestra inteligencia dispone o no de un hábito cognoscitivo, pues es la voluntad

${ }^{92}$ De rationibus fidei, cap. 3 co.

${ }^{93} \mathrm{~S}$. Decretalem, n. 1, co.

${ }^{94}$ S. Theol., I, q. 107, a. 1, co. El texto sigue así: "similiter autem et de secundo gradu transfertur in tertium per voluntatem, nam per voluntatem conceptus mentis ordinatur ad alterum, puta vel ad agendum aliquid, vel ad manifestandum alteri" (id.). 
la que puede usar de él. La cuestión, por tanto, es: ¿usa la voluntad del hábito conceptual para que este hábito ejerza actos de concebir?

Según Tomás de Aquino, la voluntad puede usar de lo concebido por la inteligencia, entendiendo ese uso en el sentido de que lo concebido permanezca en la mente o se manifieste al exterior. ${ }^{95}$ Ahora bien, ¿̇ignifica eso que de la voluntad depende que el hábito de la inteligencia ejerza o no sus actos, obviamente, no en el sentido de que se cambie la índole del hábito, sino que del estado de hábito se pase al estado de operación? Para Tomás es claro que la voluntad puede actuar sobre lo concebido, siempre que lo sea como bien, pues el bien conocido es el objeto de la voluntad. ${ }^{96}$ Además, en las acciones prácticas que se van a realizar, la voluntad toma lo concebido como una forma para transformar la realidad exterior de acuerdo con ella. ${ }^{97}$ Pero de lo que precede no se deduce explícitamente que la voluntad use del hábito conceptual. De manera que la cuestión queda abierta en el corpus tomista.

¿Qué se puede añadir al respecto? Que sin duda existe un hábito al que podemos llamar conceptual, sencillamente porque nos damos cuenta de que concebimos; es decir, somos conscientes de nuestros actos de concebir, no sólo de los asuntos concebidos. Pero este darnos cuenta no puede correr a cargo de la potencia, pues ésta sin ser activada no conoce. Tampoco a cargo del propio acto de concebir, porque ningún acto cognoscitivo es reflexivo, pues de serlo, no podría distinguir entre lo concebido (el compuesto hilemórfico, que es físico) y el propio acto de concebir (que es inmaterial).

\footnotetext{
95 "Ipsa voluntate, conceptum intellectus potest retinere interius, vel ad extra ordinare" (S. Theol., I, q. 107, a. 1, ad 1). En el cuerpo del artículo se lee: "nihil est enim aliud loqui ad alterum, quam conceptum mentis alteri manifestare" ( $S$. Theol., I, q. 107 a. 1 co.). Precedentemente había escrito: "per modum voluntatis, nam inclinatio eius ad agendum quod intellectu conceptum est, pertinet ad voluntatem" (S. Theol., I, q. 19, a. 4, co.); cfr. asimismo: De Ver., q. 9, a. 4, ad 15.

96 "Cum bonum intellectum sit proprium obiectum voluntatis, cuiuslibet per intellectum concepti potest esse voluntas ubi salvatur ratio boni" (S.C. Gentes, lib. I, cap. 81, n. 3).

97 "Posita actione, sequitur effectus secundum exigentiam formae quae est principium actionis. In agentibus autem per voluntatem, quod conceptum est et praedefinitum, accipitur ut forma quae est principium actionis" (S. Theol., I, q. 46, a. 1, ad 10).
} 


\section{BIBLIOGRAFÍA}

Alarcón, E., "El debate sobre la verdad", en P. Pérez-Ilzarbe y R. Lázaro (comps.), Verdad, bien, belleza, Servicio de Publicaciones de la Universidad de Navarra, Pamplona, 2000, pp. 35-62 (Cuadernos de Anuario Filosófico, 103).

Cayetano, T. De V., In Summa Theologiae, I P., q. 15, a. I, VIII, ed. Leonina, Roma, vol. 4, 1888.

Cruz, J., Intelecto y razón. Las coordenadas del pensamiento clásico, Eunsa, Pamplona, 1982.

Doig, J.C., "O'Callaghan on verbum mentis in Aquinas", American Catholic Philosophical Quarterly, vol. 77, 2003, pp. 233-255.

Escoto, D., Distinctionum et quaestionum libri primi Sententiarum, d. XXXVI, q. Unic. Opera Omnia, Ludoricum Vivés, París, vol. 10, 1969.

Floucat, Y., Lintime fécondité de l'inteligence. Le verbe mental selon saint Thomas d’Aquin, Téqui, París, 2001.

Garceau, B., Judicium, vocabulaire, sources, doctrine de Saint Thomás d'Aquin, Institut d'Études Médiévales, Montreal, 1968.

Hoenen, O., "De origine principiorum scientiae", Gregorianum, vol. 14, 1933, pp. 153-184.

Ignotus auctor, De sacramento Eucharistiae, en Corpus Thomisthicum, Opera

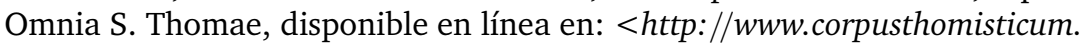
org/>.

Lonergan, B., La Notion de verbe dans les écrits de saint Thomas d'Aquin, Beauchesme, París, 1966.

Maritain, J., Distinguir para unir o los grados del saber, Club de Lectores, Buenos Aires, 1968.

Meissner, W.W., "Some Aspects of the verbum in the Texts of St. Thomas", The Modern Schoolman, vol. 36, 1958, pp. 1-30.

Moya, P., El principio del conocimiento, Eunsa, Pamplona, 1994.

O'Callaghan, J., "More Words on the verbum: A Response to James Doig", American Catholic Philosophical Quarterly, vol. 77, 2003, pp. 257-268.

- "Verbum mentis: Philosophical or Theological Doctrine in Aquinas?", Proceedings of the American Association, vol. 74, 2000, pp. 103-119.

O'Connell, M.J., "St. Thomas and the verbum: An Interpretation", The Modern Schoolman, vol. 24, 1947, pp. 224-234.

Ockham, G., Summa Logicae I, c. 19, Opera Philosophica, The Franciscan Institute St. Bonaventure, Nueva York, vol. I, 1957.

Pedro Abelardo, Historia calamitatum, Biblioteca de Autores Cristianos, Madrid, vol. I, 1949.

Peghaire, J., Intellectus et ratio selon S. Thomas D'Aquin, Institut D' Etudes Médiévales D’Ottawa, París/Ottawa, 1936.

Polo, L., Curso de teoría del conocimiento, vol. III, 2a. ed., Eunsa, Pamplona, 1999.

—- Curso de teoría del conocimiento, vol. IV, 2a. ed., Eunsa, Pamplona, 2004.

Diánoia, vol. LIII, no. 61 (noviembre 2008). 
Polo, L., El conocimiento racional de la realidad, Servicio de Publicaciones de la Universidad de Navarra, Pamplona, 2004 (Cuadernos de Anuario Filosófico, Serie Universitaria, no. 169).

Ramírez, S., "Utrum aliquis habitus sit a natura", De habitibus in commune, Opera Omnia, C.S.I.C., Instituto de Filosofía "Luis Vives", Madrid, vol. VI, 1973.

Sanguineti, J.J., Ciencia aristotélica y ciencia moderna, Educa, Buenos Aires, 1991.

- La filosofía de la ciencia según Sto. Tomás, Eunsa, Pamplona, 1977.

Sellés, J.F., Conocer y amar. Estudio de los objetos y operaciones de la inteligencia y de la voluntad según Tomás de Aquino, 2a. ed., Eunsa, Pamplona, 2000.

Tomás de Aquino, Corpus Thomisthicum, Opera Omnia S. Thomae, disponible en línea en: <http://www.corpusthomisticum.org/>.

Trotmman, C., "Verbe mental et noetique thomiste dans le De verbo d'Herve de Nédellec", Revue Thomiste, vol. 97, 1997, pp. 47-62.

Urdanoz, T., Suma Teológica de Santo Tomás de Aquino. Tratado de los hábitos y virtudes, Biblioteca de Autores Cristianos, Madrid, vol. V, 1954.

Recibido el 8 de agosto de 2006; aceptado el 21 de noviembre de 2007. 